\title{
Tensiones de lo femenino/masculino en los espacios escriturales de Gabriela Mistral*
}

\author{
Tensions of femininity/ masculinity in the \\ writing of Gabriela Mistral
}

Francisco García Mendoza**

\begin{abstract}
RESUMEN
En este ensayo se contrastan los espacios escriturales presentes en Gabriela Mistral. Se propone el poema "La otra" como una de las marcas que evidencian la esci.sión del yo, estableciendo de ese modo una escritura de carácter público y otra relegada al ámbito de lo privado. A partir de la propuesta anterior, se revisa la correspondencia con su albacea Doris Dana desde una perspectiva literaria, para hallar las marcas que confirmen la propuesta sugerida en el poema "La otra" y así intentar establecer las huellas de lo femenino y lo masculino en su escritura. La interpretación y lectura de su obra poética permite confirmar la impostación que utiliza Mistral para validarse en el canon poético nacional.
\end{abstract}

\section{SUMMARY}

This essay contrasts the writing of Gabriela Mistral. The poem "La otra" (In English: The other) shows the division of the self, thus establishing a writing of a public nature and another relegated to the private sphere. Based on that assumption, the essay reviews Mistral's correspondence with her executor Doris Dana from a literary perspective, to confirm the proposal suggested in the poem "La otra" and thus tries to establish traces of the feminine and the masculine in her writing. Interpreting and reading her poetic work shows the techniques used by Mistral to validate herself in the national poetic canon.
Palabras clave:

Poesía, cartas, femenino/ masculino, público/privado.

Keywords: Poetry, letters, female / male, public / private.

* Este artículo es resultado de una investigación del seminario "Crítica Literaria" en 2019, impartido por la Doctora Rubí Carreño Bolívar, en el marco del programa de Doctorado cursante en la Pontificia Universidad Católica de Chile.

** Chileno. Candidato a Doctor en Literatura de la Pontificia Universidad Católica de Chile, Santiago, Chile.frgarcia2@uc.cl 


\section{Introducción}

La diferencia entre los espacios escriturales públicos (los poemas) y los privados (las cartas) puede ser abordada desde el desdoblamiento de la sujeto en el poema "La otra" (2010) y desde esa escisión es, además, posible acceder a una interpretación que tensiona las lecturas con la correspondencia con su albacea Doris Dana.

El poema "La otra", incluido en el apartado "Locas mujeres" de $L a$ gar, funciona como pivote de gran parte de su obra escritural, en el sentido de que es posible leer la escisión entre el yo público y el privado al que Mistral se aferra para sostener y validar su obra en un canon que relega la escritura de las mujeres a un espacio más bien subordinado.

La propuesta de este análisis tiene que ver con el orden genérico, en donde lo masculino se erige como lo canónico/universal y lo femenino aparece desbordante a esa subyugación histórica. Bien podría caer este ensayo en un análisis biograficista de Gabriela Mistral, porque no es ajena a nadie la tensión entre su vida privada y su representación pública. Sin embargo, la propuesta surge de la necesidad de abordar las cartas no desde una perspectiva literal, sino más bien literaria. Las interpretaciones realizadas quedan exclusivamente acotadas a los espacios escriturales de la poeta, aunque es imposible no tender puentes hacia su persona.

¿Cuáles son las marcas de lo femenino y lo masculino en su escritura? ¿Es posible hacer coincidir lo masculino con lo público y lo femenino con lo privado en Gabriela Mistral? ¿Es posible relacionar ambas? A partir de estos cuestionamientos y de la fisura leída en el poema "La otra", se intenta aquí hacer una lectura literaria de la correspondencia entre Mistral y Dana, como un modo de acceder a su quehacer escritural y así seguir contribuyendo a la ampliación y resignificación de su escritura.

\section{La fuerza del canon}

La figura de Gabriela Mistral aparece en un canon predominantemente masculino. La primera Nobel latinoamericana viene a ocupar un espacio reservado para los hombres dentro de todo el laureado panteón de poetas nacionales. Los nombres de Teresa Wilms Montt, Winnét de Rokha, Olga Acevedo, María Tagle o María Monvel, son prácticamente 
desconocidos fuera de los ámbitos académicos que se dedican a estudiar la poesía escrita por mujeres de la primera mitad del siglo XX. Incluso hoy en día, las poetas en ejercicio siguen siendo invisibilizadas de la tradición poética nacional. Hasta antes de la revolución feminista, que desde hace un par de años ha hecho temblar los pilares de lo universal/masculino, los espacios dedicados a difundir la poesía de Elvira Hernández, Eugenia Brito, Malú Urriola, Soledad Fariña, Rosabetty Muñoz o Carmen Berenguer, eran más bien restringidos a ciertos lugares culturales específicos.

No hay duda de que Gabriela Mistral viene a ser una sujeto rara dentro de la hegemonía poética masculina. Rara en el sentido de extraña, inusual, mujer que superó los espacios dispuestos para las mujeres de su tiempo, pero rara también en el sentido de su ambigüedad sexual que favoreció la construcción de su figura como maestra y madre simbólica de la nación ${ }^{1}$. No deja de ser curioso que una sujeto con dichas características haya ocupado un rol tan relevante en la construcción de la identidad nacional, considerando que el resto de los raros eran perseguidos por el Estado y sometidos al escrutinio violento de las experimentaciones médicas. La académica Magda Sepúlveda comenta: "La dictadura de Pinochet construyó una Mistral materna, cuya función era el ejercicio fuerte y severo de la educación de los hijos. Esta imagen puede verse en el primer billete de cinco mil pesos creado en 1981, donde una Mistral de perfil mira la escultura de una madre con sus hijos" ${ }^{2 \prime}$ (23). Esta construcción de Mistral sin duda está motivada, además, por la necesidad del régimen de atenuar la relevancia del poeta comunista Pablo Neruda. Por su parte, la académica y crítica literaria Raquel Olea señala en su libro Variaciones (2019) que:

El mandato a ser mujer chilena: madre, esposa (aunque no fuera ni lo uno ni lo otro), maestra amante de niños, mujer católica, adscrita al orden de lo familiar, la despojó de su singularidad, situándola en el imaginario social como mujer carenciada y marginalizada. Solo

1 Al respecto puede consultarse el estudio crítico A Queer Mother for the Nation: The State and Gabriela Mistral publicado por Licia Fiol-Matta, cuya traducción al castellano permanece pendiente.

2 Es interesante hacer la comparación con el billete actualizado de cinco mil pesos, rediseñado en democracia, en donde se opta por una Mistral más joven, de rasgos suavizados. Un retrato que privilegia la frontalidad cercana en vez del perfil más bien severo. 
así podía ser admitida en la institucionalidad del país. Para ingresar al canon nacional, debía cumplir el reglamento. (203)

Mistral aparece entonces como una figura en permanente disputa, una construcción que responde más bien a intereses políticos e ideológicos que se apropian de su significación y tensionan su representación simbólica. En el mismo texto Olea reafirma:

En este recorrido aún en curso, su imagen se ha pluralizado, diversificado y densificado de sentido, poniendo en crisis las miradas oficiales con que se la instaló culturalmente, desde sus inicios. La figura de Mistral no ha estado ajena a las disputas discursivas con que los poderes sociales producen, desplazan, construyen y manipulan los íconos culturales y sociales, representativos de la identidad nacional. (204)

Por otra parte, la investigadora Lorena Garrido (2012), que en parte aborda las estrategias de la poeta para alcanzar un sitial reservado para los hombres, señala que: "No es necesario observar con demasiada atención para darnos cuenta de que las grandes corrientes del pensamiento poético y metapoético en Occidente fueron forjadas por una voz masculina que es la que finalmente se transformó en canon" (20). En esa línea, es interesante constatar las lecturas de la obra mistraliana desde la significación religiosa, maternal y amorosa, que responde en gran parte a la interpretación de una crítica más bien hegemónica que apunta, señala y sitúa.

El patriarcado poético obliga a las escritoras a asumir una voz otra, neutral en el mejor de los casos, para llegar a ser consideradas. La escritura pública/publicada de Mistral es ampliamente conocida y estudiada, repetida incansablemente en las escuelas del país, tanto así que aún hoy es reconocida como la autora de los "piececitos de niño azulosos de frío" o de las inocentes rondas infantiles.

En 2007, Doris Atkinsons entrega al Estado de Chile la correspondencia entre la poeta y su albacea, Doris Dana, donde más allá de confirmar la relación amorosa entre las dos, deja en evidencia la voz que Mistral acalló fervorosamente en su escritura pública. Este hecho revela el espacio escritural que la poeta quiso mantener privado para privilegiar así la voz que finalmente fue asimilada por el canon poético masculino nacional. 
Se ha leído a Gabriela Mistral como han dicho que debe ser leída. Sin embargo, hay que enfrentarse también a la dificultad de que no son solo sus guardianes quienes han forzado las lecturas de su poesía, pues como señala Grinor Rojo (1997):

Para reencontrarnos con la otra Gabriela, nosotros tuvimos que raspar esta costra blanqueadora. Con el añadido de que también debimos enfrentarnos con el hecho de que fue la propia poeta quien estimuló con frecuencia las acciones bienpensantes de sus críticos, aportando una colaboración entusiasta a las campañas reduccionistas a las que ellos daban curso con su perversa devoción. ("Gabriela Mistral..." 53)

Respecto de la construcción de la propia poeta como personaje, más allá de su transición de Lucila Godoy a Gabriela Mistral, Sepúlveda apunta:

No es solo cambiarse el nombre recibido al nacer, sino que es inventar una subjetividad para esa nueva denominación y lograr que su discursividad sea reconocida por la comunidad ... Ella tuvo que luchar por ocupar, e incluso polemizar, con las posiciones que el circuito legitimador ofrecía a las mujeres ... La mayor dificultad que tenía una mujer que entraba al campo cultural, era la forma como era leída. Su escritura era reducida a la biografía de sus amores y se le creaba un personaje atormentado y trágico. (169)

En el año 2002, el escritor y académico Juan Pablo Sutherland (2002) intentó sin éxito incluir tres poemas de Mistral en su antología literaria de la homosexualidad chilena para tensionar la impostación, siendo el permiso denegado por la fundación a cargo de su obra. En ese momento la respuesta fue categórica. Sutherland escribe:

En una carta enviada por la Fundación Gabriela Mistral, se señala que "dicho trabajo antológico puede contribuir a interpretaciones tendenciosas, antojadizas y especulativas contrarias a la siempre significativa y relevante obra de nuestra autora". Resulta sorprendente que todavía existan prácticas prohibitivas de las distintas lecturas que se vienen haciendo desde hace mucho tiempo en la obra mistraliana. (22)

Esta respuesta confirma la hipótesis de que, al menos hasta el año de publicación de la antología de Sutherland, a nivel oficial las lecturas 
de la obra de Gabriela Mistral fueron conducidas, irónicamente citando a la propia fundación, de manera tendenciosa.

A partir del día en que su correspondencia comenzó a abandonar el ámbito de lo privado, no fueron pocos los que insistieron en negar lo que a grandes luces ya era evidente: "Mistral era inexpugnable en el aspecto de su vida privada. La decisión de reserva total sobre su vida íntima, especialmente sobre su opción sexual fue clave para tener cierta aceptación en el campo cultural chileno, donde hasta el siglo XXI existen dificultades para aceptar que Mistral no estaba heteronormada" (Sepúlveda 183).

En un artículo de prensa de Rodrigo González (2011) publicado en el diario La Tercera, once años después de la antología de Sutherland, en relación con el estreno del documental Locas mujeres de María Elena Wood, Pedro Pablo Zegers comentó que: "Con la mentalidad y el temperamento tradicional que tenemos los chilenos nos negamos en su momento a conocer a una Gabriela Mistral diferente" (s/n). Otros estudiosos de su obra (y celadores de su imagen) como Luis Vargas Saavedra o Jaime Quezada, se seguían resistiendo y fueron categóricos al afirmar que "Sabemos que Mistral se desesperaba cuando no veía por mucho tiempo a Doris Dana. Por eso hay que aceptar que Dana sí era lesbiana y que Gabriela Mistral la aceptaba a ella" ( $\mathrm{s} / \mathrm{n})$. En otras palabras: la culpable de ser lesbiana es Dana y Mistral -tal y como el sujeto heterosexual sobre el que no lo es-, acepta (o no) esa condición minoritaria. Al respecto, es interesante reflexionar y problematizar la validación y legitimación que enuncia el sujeto hegemónico sobre el minoritario. El "eres diferente a mí, pero te acepto como eres" no es sino una expresión que continúa reproduciendo las lógicas de dominación y desigualdad entre las personas.

Más allá del gesto paternalista de la aceptación y apuntando más bien a sus poemas, la académica Raquel Olea señaló en la misma entrevista que "no se puede separar su obra de su condición de lesbiana. Hay una subjetividad particular de una mujer homosexual que atraviesa sus textos. No se los puede ver como si hubieran sido escritos por una mujer heterosexual" (s/n). En ese sentido, según Olea habría ciertas marcas o indicios que revelarían un deseo, un género o un rol simbólico distintivo que fisuraría lo masculino/heterosexual en su escritura, tendiendo inevitablemente, como mencio- 
né, un puente entre su producción literaria y su biografía. Al respecto es interesante el trabajo realizado por Lila Zemborain, quien en Gabriela Mistral: una mujer sin rostro (2002) le dedica un capítulo al análisis del desdoblamiento del yo en la instauración de su seudónimo autoral, una firma que según la investigadora, generaría relaciones entre texto y autora, una poética relacional que tiende, al mismo tiempo, al silenciamiento y a la insubordinación, pues como bien señala la argentina: "Gabriela Mistral como seudónimo o nombre de autor nace de las cenizas del nombre de Lucila Godoy” (33). En ese sentido, más que una correspondencia biográfica, lo que habría en las huellas señaladas por Olea sería la confirmación de una pulsión minoritaria capaz de desbordar los márgenes de la textualidad/ sexualidad.

$\mathrm{Si}$ atendemos a la tesis de que a lo largo del siglo XX las escritoras tuvieron que impostar una voz y recurrir a ciertas estrategias para que su obra fuese asimilada y aceptada tanto por la crítica como por los lectores, es necesario practicar un análisis minucioso para encontrar esas marcas o indicios a los que se refería Raquel Olea en la entrevista. Más aún, debido a las interpretaciones y lecturas oficiales impuestas por las diversas instituciones, incluido el Estado chileno que ha instaurado finalmente una figura artificiosa de la poeta en el imaginario nacional, se hace imperiosa una deconstrucción tanto de su persona como de su poesía.

Existe una clara diferencia entre su escritura pública (los poemas) y su escritura privada (la correspondencia con Doris Dana). Entre ambas escrituras hay maneras que concuerdan, otras que no calzan, distancias insondables entre los espacios textuales, pero también aparecen ciertos elementos que configuran puentes entre su poesía y su epistolario. En ese sentido, el poema "La otra" puede leerse como una de las tantas marcas que permiten el ingreso a su escritura más privada desde la literatura, pudiendo así establecer huellas distintivas tanto de lo femenino como de lo masculino en su amplitud textual.

\section{La muerte del yo escritural en "La otra"}

¿Cómo se entiende el desdoblamiento mistraliano? ¿Desde qué base se parte para hablar de dos espacios de escritura en una misma persona? La tensión entre su yo privado y su yo público se aprecia tam- 


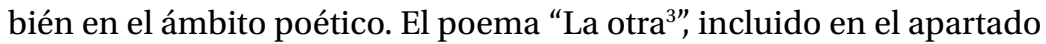
"Locas mujeres" de Lagar, es uno de los múltiples ejemplos de la escisión del yo poético mistraliano. Es interesante la apreciación que realiza Magda Sepúlveda cuando comenta: "Desde mi punto de vista, en la sección "Locas mujeres", Mistral va a poetizar historias de mujeres que se han construido fuera de los cánones de la femineidad deseable para inicios del siglo XX" (123). En ese sentido, apunta a la reflexión en torno a la mujer latinoamericana a través del apelativo "loca", el que apunta, señala y sitúa a una sujeto que está fuera de la norma, que no calza con los preceptos hegemónicos y que incomoda desde su posición inclasificable ${ }^{4}$.

En este poema hay una suerte de espejeo entre dos sujetos que se oponen, pero que se necesitan mutuamente para existir. La hablante es "la otra", presentada en el título del poema, y se refiere o habla en el corpus de una sujeto "una", la que mató, la que ya no existe. Se presenta entonces una dicotomía en el espacio escritural: aparece la sujeto pública (la otra) y la privada (la una):

Una en mí maté:

yo no la amaba.

Era la flor llameando

del cactus de montaña;

era aridez y fuego;

nunca se refrescaba. (339)

La "una" responde a una sujeto pasional, desbordante, "la flor llameando", la que "nunca se refrescaba", la asociación semiótico-pulsional a la que se refiere Kristeva en Revolution in Poetic Language (1974) y que enmarca dentro de lo propiamente femenino ${ }^{5}$. La "otra", en cambio, es todo lo contrario. Se percibe cierta incomodidad con la sujeto muerta,

3 Ver la interesante lectura que realiza de este poema Raquel Olea en su libro Como traje de fiesta (2009) y que, en parte, fue la justificación inicial para este ensayo.

4 La figura de la "loca" es abordada por Pedro Lemebel en su vasta producción literaria. En ese sentido, sujeto mujer y homosexual han sido situados en similar espacio de subordinación respecto del sujeto hegemónico. Tanto Mistral como Lemebel se apropian y resignifican el insulto de "loca", dotándolo, de ese modo, de una carga más bien política que se erige como hito de resistencia al discurso patriarcal.

5 En Masculino/femenino (1989), Nelly Richard se refiere a las teorizaciones que plantea Julia Kristeva, en donde identifica lo semiótico-pulsional con lo femenino. 
pues la "una" es la rara, la que no calza. "La otra", en cambio, es la mujer disfrazada y asimilada a lo que el discurso masculino propone y entiende como mujer. Mistral, a fin de cuentas, debe escribir desde cierta femineidad impostada e institucionalizada para ser aceptada por los hombres: no puede ser totalmente masculina ni cien por ciento femenina, debe jugar con esa mascarada para que el crítico la reconozca como otra y, a la vez, la acepte como parte de los suyos. La estrategia consiste en asimilarse al patriarcado y actuar/representar desde la masculinidad una política escritural. Ana Pizarro propone una lectura donde: "Gabriela Mistral elabora desde la mujer el discurso de la subalternidad, un discurso que juega con los resquicios, que elabora artimañas, y que en su estrategia formula su imagen" ("Gabriela Mistral en..." 107).

Refiriéndose a esa otredad representada por "la una", Raquel Olea, en su libro Como traje de fiesta (2009) y basándose en los postulados de Todorov, afirma que: "lo otro es todo lo que está fuera del orden de las representaciones y del sistema de normas de la cultura logocéntrica de occidente; lo otro está fuera de ese orden simbólico. La mujer no tiene cabida en este discurso del otro" (102). Mistral debe entonces masculinizarse para ser aceptada, ser una "otra". Similar estrategia adoptó Marta Brunet, quien fue galardonada con el Premio Nacional de Literatura el año 1961.

Más adelante en el poema, la hablante continúa refiriéndose a la sujeto pasado: “La dejé que muriese,/ robándole mi entraña./ Se acabó como el águila/ que no es alimentada ..." (340). En los dos primeros versos se lee cómo la hablante afirma que dejó morir a la "una", pasivamente casi, pero aclara que lo ha hecho "robándole mi entraña". Es decir, quedándose o arrebatándole algo que por derecho le pertenecía, la interioridad, lo más profundo, íntimo y esencial, oculto y protegido, la índole y el genio. Olea ve aquí a "la amante, la intrusa, la querida, la prostituta, la no madre de los hijos, la concubina" (Como traje... 103). En este listado se puede incluir, sin mayores complicaciones, también a la sujeto lesbiana. Todas subjetividades que, de una u otra manera, incomodan al orden masculino. No como esa "otra", en cambio, que viene a ser la esposa, madre, maestra, la que sufre, la poeta o, a final de cuentas, la mujer pública.

Por otra parte, en los dos siguientes versos de este cuarteto, la hablante compara la muerte de la "una" con la muerte de "el águila/ que 
no es alimentada" (340). La muerte de un animal majestuoso, imponente, respetable, pero pausada y agónica, no exenta del dolor que significa morir de a poco. En ese sentido, se puede afirmar que el asesinato de la "una" no fue fácil, sino que más bien implicó un proceso de muerte lenta, incómoda, dejando incluso espacio para el arrepentimiento o la piedad. Por eso, más que una muerte violenta y certera, es una lucha interna, dolorosa, difícil de ejecutar y sobrellevar, para excluir a la sujeto que no calza.

La muerte de esa "una" la describe en la siguiente estrofa: "Sosegó el aletazo,/ se dobló, lacia,/ y me cayó a la mano/ su pavesa acabada" (340). Cuando la hablante dice que finalmente "sosegó el aletazo", es donde se evidencia que la "una" terminó por ceder no sin antes aletear por su vida. No fue una muerte pasiva - se lee ahora-, sino que implicó una lucha, una resistencia vital por parte de la sujeto que ahora yace muerta.

Esa sujeto queda enterrada, exiliada para siempre del espacio público y recluida en el privado. Sin embargo, esa "águila" no muere del todo. Esa pavesa es la ceniza que ha quedado de una materia inflamada. El águila de este poema tiene, además, la fuerza y gracia del fénix. De hecho, en la siguiente estrofa la hablante evidencia que esa "una" permanece latente y en estado potencial en los restos acogidos por la tierra:

Por ella todavía

me gimen sus hermanas,

y las gredas de fuego

al pasar me desgarran.

Cruzando yo les digo:

-Buscad por las quebradas

y haced con las arcillas

otra águila abrasada.

Si no podéis, entonces,

¡ay!, olvidadla.

Yo la maté. ¡Vosotras

también matadla! (340)

Se aprecia nuevamente la incomodidad de la hablante con la sujeto aparentemente muerta. Aún le atormenta esa criatura relegada. Pero en la segunda estrofa, deja claro que esa "una" no volverá, es defini- 
tivo, no hay intenciones de hacerla renacer. Les dice a las que gimen que busquen por otro lado, que hagan otra águila de greda con sus restos arcillosos. Que su pasión desbordante ya no existe en ella, "la flor llameando", descrita en la primera parte del poema permanecerá para siempre desterrada.

Sobre la mujer, la investigadora Lorena Garrido señala que: "La poeta es considerada un ser diferente en la poesía de Mistral: habla una lengua diferente, tiene un dios diferente, siente y vive de manera diferente" (382). En ese sentido, el poema "La otra" viene a ser una huella del desdoblamiento que se produce en Mistral entre su yo poeta y su yo íntimo. Al respecto señala Grinor Rojo que "la fractura existe en la poesía mistraliana desde siempre y hasta siempre, antes, entonces y después" (Dirán que 52). Lo que hace suponer que las marcas o huellas del desdoblamiento del yo no queda remitida exclusivamente a este poema, sino que está presente en otros espacios de su obra. Mistral procura establecer una identidad a partir de esa fragmentación del sujeto discursivo, una identidad tránsfuga, siempre desplazándose, identidad que, finalmente, va a configurar su quehacer poético público.

\section{Niña errante: Lo femenino y masculino en su yo escritural}

El epistolar ha sido históricamente catalogado como un género menor dentro de los estudios literarios. Por su carácter más bien íntimo, que remite al espacio de lo privado, ha sido pensado, además, como un género propiamente femenino. Magda Sepúlveda afirma que: "Mistral guardó reserva sobre su vida, entre otras causas, porque sabía que la crítica de la época reducía la escritura de las mujeres a un folletín melodramático" (174).

Más allá de lo que se ha dicho sobre este tipo de escritura, que ofrece un exquisito relato testimonial de la relación entre dos mujeres, se puede acceder a ellos también desde una trinchera más bien literaria. A partir del desdoblamiento de la sujeto en el poema "La otra" es posible abordar esta escritura desde una perspectiva que cruza ambos géneros. $\mathrm{Si}$ se entiende el poema como la enunciación de una dicotomía escritural, en donde la poesía se enmarca en el ámbito de lo público, asumiendo una mascarada para lograr aceptación, y su correspondencia se relega al espacio escritural de lo privado, se puede plantear este intercambio 
epistolar con Dana como testimonio literario en donde existen ciertas marcas que remiten al quehacer poético de Mistral. En esta línea, es relevante revisar lo que plantea Diamela Eltit (1990) en "Personaje en correspondencia" acerca de la ficción e impostura en su correspondencia:

Examinando cualquier correspondencia, es posible vislumbrar el modo de relación, estructurado en una zona imaginaria, en la cual tanto el que escribe como su destinatario se construyen como personaje ... el sujeto se modifica en su aproximación al otro, y por esto cada correspondencia elabora un sujeto particular, sujeto determinado por el tipo de relación que establece. (49)

Quizá lo que más llama la atención en una primera lectura de las cartas, compiladas y editadas por Pedro Pablo Zegers (2010), es la masculinización gramatical de la Nobel: "Y yo no debí escribirte en tal estado de ánimo, pero soy arrebatado, recuérdalo, y colérico, y TORPE, TORPE. Por favor, no vuelvas nunca-nunca a sufrir así, a padecer por mi culpa" (54).

El asumir una voz diferente a la que la norma impone puede considerarse un acto político si es que se realiza y atiende en un espacio más bien público. Sin embargo, en una carta privada es difícil que dicho gesto constituya algún tipo de activismo. Por el contrario, más certero sería considerarlo como la enunciación de una voz auténtica, libre de la impostación poética o literaria que puede observarse en sus poemas. Sin embargo, si bien Mistral en sus cartas a veces utiliza el masculino, vuelve otras tantas al femenino referencial, por lo que su autorrepresentación -siguiendo a Eltit- lejos de inscribirse en una categoría fija del binarismo femenino/masculino, transita por la fluidez genérica de la indeterminación. En su correspondencia con Dana, Mistral huye de la determinación identitaria que exige la sociedad de su tiempo.

Casi una década después de la fallida inclusión de Mistral en la antología de Sutherland (2001), el editor de Niña errante (2010) advierte al lector sobre esta elección de la poeta: "a medida que avanzan las cartas en el tiempo, Gabriela adquiere una función gramaticalmente masculina en las huellas formales de sus cartas. Esto podría leerse como un ascendente de carácter paternal y protector y que, por su parte, Doris Dana, a pesar de su propia independencia y holgada situación económica, acepta sin dudar" (17). 
Es interesante notar cómo los celadores de su obra siguen intentando mantener esa lectura tradicional y asexuada que se ha hecho de la escritura de Mistral. Zegers se esmera en que no se realice una lectura "tendenciosa” de su obra. Más aún, le resulta extraño que, pese al estatus social y económico de Dana, ella acepte ese gesto de la poeta. Como si lo aceptable estuviese estrictamente ligado a un orden de clases.

Más adelante, en una nota del editor de Niña errante, se propone que la inflexión de Mistral obedece

más que [a] un gesto de sexualidad, a una actitud de padre protector y proveedor, aspecto que si bien resulta comprensible en el caso de Gabriela, quien necesita mantener su estatus de maestra, mostrar gestos de superioridad generosa, por decirlo de alguna manera, es extraño en el caso de la respuesta de Doris, que acepta un tanto lúdicamente este trato, considerando que ella provenía de una familia que contaba con considerables medios económicos. (24)

Los encargados de la publicación insisten en hablar por Mistral, situar los parámetros de lectura y enfatizar en la posición económica y social como una suerte de juzgado de la moralidad y lo aceptable. Se les concede, eso sí, el reconocimiento de una Mistral que necesita mantener una mascarada, estatus que constituye, a final de cuentas, su yo público. Al respecto, Raquel Olea afirma:

Es interesante observar que su imagen y este pensamiento tan potente, en Mistral, hayan sido subordinados en las políticas oficiales a la construcción de un ícono nacional, orientado hacia la recepción situada en una figura de mujer, exigida por los discursos dominantes que no pudieron o no se dieron el trabajo de pensarla y aceptarla en la complejidad y la potencia de su pensamiento y disidencias (Variaciones... 203).

La resistencia al discurso oficial, a la institución de la lengua, se aprecia en estas huellas del yo masculino, y se ampara dentro del discurso femenino en cuanto voz contestataria, que evade la norma de lo que se considera femenino o masculino. En algunas de las cartas de Mistral aparece el gesto de utilizar un yo masculino como desacuerdo con el discurso de la oficialidad, de la norma y de lo dominante. Al respecto señala Richard (1989) que: 
Cualquier literatura que se practique como disidencia de identidad respecto al formato reglamentario de la cultura masculino-paterna ... cualquier escritura en posición de descontrolar la pauta de la discursividad masculina/hegemónica compartiría el "devenir minoritario" (Deleuze-Guattari) de un femenino que opera como paradigma de desterritorialización de los regímenes de poder y captura de la identidad normada y centrada por la cultura oficial. (35-36)

Gabriela Mistral utiliza la huella masculina, justamente, para rechazar lo masculino en cuanto a norma. La poeta está plenamente consciente del fingimiento estratégico de su quehacer escritural. Sus gestos políticos en el ámbito de la disidencia de género quedan relegados a su escritura privada y no hay un interés real en que se muevan de ese espacio. De hecho, manifiesta el temor de que su correspondencia salga a la luz cuando le comenta a Dana: "Me parece muy mal el que se pierdan cartas. Eso es muy peligroso. Yo puse por mis manos tres al correo, una hoy y mañana irá otra" (Niña errante 58). Su yo escritural femenino (la disidencia genérica) debe quedar relegado estrictamente a lo privado, pues hacerlo público pone en riesgo su impostación poética, viéndose afectada la posición que ha logrado construirse en el canon literario. La estrategia de Mistral de ser asimilada por la crítica misógina requiere que la correspondencia con Dana no sea conocida.

Bien podría decirse que el asumir una gramática masculina en sus cartas echa por la borda la identificación con lo femenino. Sin embargo, la inversión de las lógicas gramaticales de la tradición, el asumir un género distinto al socialmente mostrado, romper con las reglas del género en la gramática, implica insubordinación hacia el universal, un rebelarse contra la oficialidad, norma que viene a representar, en el lugar de poder, la masculinidad.

En una carta fechada en abril del 1949, Mistral, distanciándose un poco de su yo, le escribe a Dana: “iQué estúpido ha sido el que más te quiere, Doris Mía! ¡Perdóname, vida mía, perdóname! ¡No lo haré más! Y tú guardarás el control de ti, y haz fe en tu pobrecillo, que es un ser torpe, vehemente y envenenado por su complejo de inferioridad (el de la edad)" (Niña errante 57). Aquí aparece la sujeto desterrada por la hablante en el poema "La otra", la sujeto pasional se manifiesta con sus contradicciones. No es estoica, la desesperación se hace evidente ante las posibles consecuencias de un error previo en su relación amorosa. 
Mistral, a pesar de todo el capital simbólico y cultura que posee, opta por retroceder frente a una Doris que ama. Los rasgos de esa sujeto confinada a lo privado, aparecen en su correspondencia cuando Mistral escribe: "Pero hay más: yo necesito de tu presencia de una manera violenta, como del aire. Parece que estuviese viviendo una asfixia. Es eso exactamente ... Loco fui, insensato, como un niño, Doris, como un niño" (Niña errante 118). Al finalizar esta carta la poeta le cuenta a Dana: "Estoy sumamente inquieto. Anoche soñé con mucho fuego. Unos dicen que es peligro; otros que es dinero" (Niña errante 120).

"La flor llameando" a la que se destierra en "La otra" se cuela en el espacio escritural de sus cartas. En ella se puede apreciar a una sujeto pasional, contradictoria y desesperada, muerta en un espacio, pero viva en el otro.

En relación con lo anterior, otra de las huellas que evidencia esa mascarada para articular y presentar su poesía, es lo que le comenta a Dana en respuesta a una de las primeras cartas que su futura albacea le escribe. Dice Mistral: "Yo soy una mujer tímida, a pesar de la dureza de mis versos" (Niña errante 30). Mistral, en esta certera frase, expresa que existe una dicotomía entre su escritura pública y su escritura privada. Le asigna a su poesía una dureza que no le es propia, asume esa característica impostada como un lugar ajeno. Porque, según Olea, "su institucionalización se produce al costo de una tensión entre vida privada y pública que ella debe sobrellevar" (Como traje... 36). Esta suerte de desdoblamiento explicaría la resistencia en cuanto a la aceptación de esta Gabriela Mistral. Con el surgimiento de esa "otra", se pone en crisis y tambalea la construcción que se ha hecho tanto de su figura como de su escritura pública.

Aludiendo a la escisión de los espacios, Grinor Rojo señala que:

... este mecanismo de creación a partir de un tachado de El Otro y de la consiguiente expropiación de su lenguaje, y que es un mecanismo que algunas escritoras latinoamericanas de generaciones posteriores, como Idea Vilariño, Alejandra Pizarnik, Elena Poniatowska, Rosario Ferré y Cristina Peri Rossi, explotarán con ánimo paródico, es una constante en el discurso de la femineidad cuando se halla a punto de abandonar el santa sanctorum de sus refugios seculares. (Dirán que... 44-45) 
Por lo que no resulta para nada descabellado identificar esa fragmentación del yo mistraliano como un discurso propiamente femenino, en cuanto rompe o pone en crisis el modelo masculino predominante en el canon poético nacional.

\section{Conclusiones}

Así como la obra de Gabriela Mistral se va duplicando en la medida en que se incorporan textos inéditos, las lecturas de su obra también lo hacen. No hay duda alguna de que la publicación de Niña errante obligó a plantear nuevas perspectivas de análisis respecto de su obra y puso en crisis otras lecturas ya institucionalizadas. La voz de Mistral no es monótona, sino que se torna difusa, contradictoria, errante, en la medida en que se profundiza en su escritura.

Tradicionalmente lo femenino ha estado ligado con la maternidad, la subjetividad de su palabra o con los signos convencionales que la oficialidad ha establecido y catalogado como tal. Sin embargo, en este análisis se ha buscado establecer las huellas de lo femenino en otro de sus espacios de escritura. De este modo, la femineidad de su discurso no solo queda relegada a los significantes o significados poéticos, sino que se amplía el horizonte a la propia reflexión y ejercicio escritural: "Entrar en la escritura poética de Gabriela Mistral es adentrarse en un territorio que hace tambalear lo que históricamente se ha pensado como femenino o feminidad" (Olea, Variaciones... 209).

En el primer apartado, se hace un recuento de la posición de la poeta en el panteón poético nacional y cómo la revelación de su correspondencia con Doris Dana produjo ciertos quiebres y resistencias entre los estudiosos y celadores de su obra y figura. Luego un análisis interpretativo plantea lo femenino de su escritura como el quiebre de la voz poética que Mistral describe en el mismo poema, estableciendo de ese modo una suerte de mascarada y una clara distinción entre los dos espacios escriturales en torno a los cuales se circunscribe este análisis: lo público y lo privado. Finalmente, en su correspondencia con Dana, se intenta identificar las huellas de ese quiebre propuesto en "La otra", en donde nombrarse hombre es jugar con la autorrepresentación y desplazar el lugar establecido para la mujer de la época. Se plantea la masculinización de su voz como un gesto de rebeldía femenina. Aquí se realiza un análisis centrado mucho más en lo literario que en lo literal. 
Aunque no hay intención directa de participar de una transformación cultural respecto del paradigma normativo - pues la poeta es más bien oblicua- cabe destacar que, además de lo revisado, Mistral explorará también otras estrategias para hacer una política desde su discurso poético. El desdoblamiento de su yo escritural constituye solo una de esas políticas de escritura en su amplia obra publicada e inédita. Más aún, queda abierta la tarea de revisar críticamente la nueva antología de su correspondencia con Dana, publicada en 2021 por Lumen, y que lleva por título Doris, vida mía; así como también los conflictos y disputas que genera su figura entre sus celadores, ahora en el campo de la ficción, en la opera prima de Elisa Clark y su novela titulada Oye Gabriela, publicada en 2021 por la editorial Los Perros Románticos.

\section{Referencias bibliográficas}

Eltit, Diamela. "Personaje en correspondencia". Una palabra cómplice. Encuentro con Gabriela Mistral. Eds. Raquel Olea y Soledad Fariña. Santiago de Chile, Cuarto Propio, 1990, pp. 49-52. Impreso.

Garrido, Lorena. No hay como una contadora para hacer contar: Mujer poeta en Gabriela Mistral. Santiago de Chile, Cuarto Propio, 2012. Impreso.

González, Rodrigo. "Expertos chilenos reconocen relación de amor entre Mistral y Dana". La Tercera, 5 de abril de 2011,https:// www.latercera.com/noticia/expertos-chilenos-reconocenrelacion-de-amor-entre-mistral-y-dana/

Kristeva, Julia. "The Semiotic and the Symbolic". Revolution in Poetic Language. New York, Columbia University Press, pp. 19-106. Impreso.

Mistral, Gabriela. “Lagar”. Gabriela Mistral en verso y prosa. Lima, Alfaguara, 2010, pp. 338-456. Impreso.

Mistral, Gabriela. Niña errante. Cartas a Doris Dana. Ed. Pedro Pablo

Zegers. Santiago de Chile, Lumen, 2010. Impreso.

Olea, Raquel. Como traje de fiesta: Loca razón en la poesía de Gabriela Mistral. Santiago de Chile, Editorial Universidad de Santiago de Chile, 2009. Impreso.

Olea, Raquel. Variaciones. Ensayos sobre literatura y otras escrituras. Santiago de Chile, Cuarto Propio, 2019. Impreso. 
Pizarro, Ana. "Gabriela Mistral en el discurso cultural". Una palabra cómplice. Encuentro con Gabriela Mistral. Eds. Raquel Olea y Soledad Fariña. Santiago de Chile, Cuarto Propio,1990, pp. 99-108. Impreso.

Richard, Nelly. “¿Tiene sexo la escritura?”. Masculino/femenino. Ed. Francisco Zegers, Santiago de Chile, 1989, pp. 35-43. Impreso.

Rojo, Grinor. Dirán que está en la gloria... (Mistral). Santiago de Chile, Fondo de Cultura Económica, 1997. Impreso.

Rojo, Grinor. "Gabriela Mistral en la historia de la mujer latinoamericana”. Re-leer hoy a Gabriela Mistral. Eds. Gastón Lillo y J. Guillermo Renart. Santiago de Chile, Universidad d' Otawa/ Universidad de Santiago de Chile, 1997, pp. 53-82. Impreso.

Sepúlveda, Magda. Gabriela Mistral. Somos los andinos que fuimos. Santiago de Chile, Cuarto Propio, 2018. Impreso.

Sutherland, Juan Pablo. A corazón abierto: Geografía literaria de la homosexualidad en Chile. Santiago de Chile, Editorial Sudamericana, 2002. Impreso.

Zemborain, Lila. Gabriela Mistral: Una mujer sin rostro. Valparaíso, Ediciones Libros del Cardo, 2018. Impreso. 